International Journal of Forensic Science \& Pathology (JJFP)

ISSN 2332-287X

\title{
Suicide Cases in Manipal, South India: An Autopsy Study
}

Charan K Shetty

Review Article

Medical Lecturer, Department of Forensic Medicine, Faculty of Medicine and Health Sciences, Universiti Sultan Zainal Abidin (Unisza), Kampus Kota, Jalan sultan mahmud, Kuala Terengganu, 21300 Terengganu, Malaysia.

\begin{abstract}
Suicide constitutes a major public health problem. It is a manifestation of self-destructive behavior that results from a crisis situation often not sufficiently recognized by relatives and friends or by the medical profession.

The present study sample consisted of 656 cases of suicide out of the 3571 total autopsy cases done in the department of Forensic Medicine, Kasturba Medical College, Manipal, Karnataka. The present study shows that the people of all age groups were involved. The highest incidence was amongst the 21-30 years (35.06\%). Male victims predominated. Present study predicts marriage as being one of the important risk factors for suicide. Most of the victims belonged to the Hindu religion $(86.4 \%)$. When we look at the presence of any past illness, 174 cases $(26.5 \%)$ were having some form of chronic physical and mental disorders at the time of committing suicides. Although seasonal variation is not much, however the present study reveals highest number of cases in summer season (36.1\%). Despair with life was the most common motive for suicide. $74.4 \%$ of the total victims in the present study used chemicals for terminating their lives and only $26.8 \%$ of the study group used physical methods for committing suicide. Amongst those who opted for physical methods, hanging was the most common (15.6\%). Among the poisoning cases, organ phosphorus poisoning (51\%) was the most commonly used method for suicide.
\end{abstract}

Keywords: Autopsy, Suicide, Methods, Poisoning, Hanging

\section{*Corresponding Author:}

Charan K Shetty.

Medical Lecturer, Department of Forensic Medicine,

Faculty of Medicine and Health Sciences,

Universiti Sultan Zainal Abidin (Unisza),Kampus Kota,

Jalan sultan mahmud, Kuala Terengganu, 21300 Terengganu, Malaysia.

E-mail:shettykishor.k@rediffmail.com

Recieved: July 21, 2014

Accepted: August 13, 2014

Published: August 19, 2014

Citation: Charan K Shetty (2014) Suicide Cases in Manipal, South India: An Autopsy Study. Int J Forensic Sci Pathol. 2(7), 50-56. doi: http:// dx.doi.org/10.19070/2332-287X-1400015

Copyright: Charan K Shetty ${ }^{\odot} 2014$. This is an open-access article distributed under the terms of the Creative Commons Attribution License, which permits unrestricted use, distribution and reproduction in any medium, provided the original author and source are credited.

\section{Introduction}

Suicide is a complex phenomenon associated with psychological, biological and social factors involving by and large every corner of the world. It is distinctively a human affair and continues to be a major public health issue. It has always attracted the attention of not only the medical fraternity but also of the philosophers and theologians.[1,2].

According to Durham, the French biologist, suicide is "death resulting directly or indirectly from a positive or negative act of the victim himself, which he knows will produce this result". Suicide from an existential point of view reflects a behaviour that seeks and finds the solution to an existential problem by making an attempt on life of the subject. Suicide is applicable to all acts terminating fatally. $[1,2,3]$
In India the National crime research Bureau (NCRB), 2010, in their annual report on Incidence and Rate of Suicides during the Decade (2000-2010) have reported that, more than one lakh persons $(1,34,599)$ in the country lost their lives by committing suicide during the year 2010. [5]

Suicide is one of the forms of criminal offence in our country. Whoever attempts to commit suicide and does any act towards the commission of such offence, shall be punished with simple imprisonment for a term which may extend to one year or with fine or with both under section 309 of the Indian Penal Code.[6]

Suicide is a long and multifactorial process and is never a consequence of a single cause or stressor. A host of biological and psychosocial components interplay in a suicide investigation. Precipitating factors may include domestic quarrels, loss of employment, financial difficulties, substance abuse, chronic disease, or mental illness.[2]

The view that suicide cannot be prevented is commonly held even among health professionals. Many beliefs may explain this negative attitude. Chief among these is that suicide is a personal matter that should be left for the individual to decide. Another belief is that suicide cannot be prevented because its major determinants are social and environmental factors such as unemployment over which an individual has relatively little control. However, for the overwhelming majority who engage in suicidal behaviour, there is a probably an appropriate alternative resolution of the precipitating problems. Suicide is often a permanent solution to a temporary problem. $[5,6]$

Considering these facts, and keeping in view the magnitude of this problem and absence of any recent data, an attempt has been made in the present study to make a complete and thorough analysis of suicides in terms of various epidemiological features, 
recent trends and to identify the risk factors associated with it which could help the health care authorities in stastical analysis as well as device a suicide prevention programmes at the state or national level

\section{Materials and Methods}

Present study is a retrospective one covering all the medico legal cases which were autopsied over a span of 20 years (January 1992May 2012). The Department of Forensic Medicine in Kasturba Medical College, Manipal, Karnataka which is located at south region on India, undertakes medico-legal autopsies of un-natural deaths occurring in its Jurisdiction of Manipal Police Station and also takes cases referred from the adjoining districts and states ie Kerala, Maharastra, Tamil nadu of southern India. In our study relevant data including the age, sex, martial staus, gender, religion, past illness, methods adopted for commiting suicide was gathered from the autopsy files maintained in the department of Forensic Medicine, Police inquest reports and Hospital case records (if available).

The manner of death was constructed as suicide or otherwise based on the inquest reports of the investigating officer

\section{Results and Observations}

A Total 3571 cases all medico legal were autopsied in the department of Forensic Medicine, Kasturba Medical College, Manipal, Karnataka during the period of 20years from January 1992 to May 2012, out of which 656 were cases of Suicide constituting $18.37 \%$ of total cases.

In our study, we observed that the highest incidence of suicide cases were found in the age group of 21-30 years which accounted for $35.06 \%$ of total cases, while the least affected group was $0-10$ years who accounted for $0.45 \%$ of total cases, as depicted in the Fig No. 1

In our study, we observed that men outnumbered women, as depicted in the Fig No. 2

Our study showed that most of the decedents were married which accounted for $(57.3 \%)$ of all the cases of Suicide, as depicted in
Fig No. 3

Most of the victims in this study were followers of the Hindu religion who accounted for $86.9 \%$ of all the cases of Suicide, followed by the Christians $8.4 \%$, Muslims $3.7 \%$ and others $0.30 \%$ respectively, as depicted in the Fig No. 4

$36.1 \%$ of the victims committed Suicide during the Summer months, closely followed by the winter season which accounted for $36.0 \%$ of all the cases, rainy season witnessed the least number of fatalities $27.9 \%$. Table No 1 .

Present study observed that despair with life was the main motive for in $79 \%$ of Suicide victims as depicted in Fig No.5

The majority of the decedents used chemical means to kill themselves and accounted for $74.2 \%$ of the total cases, Physical method was used by the remaining victims of Suicide as Depicted in Fig No.6

One fourth of the total population studied (25.8\%) opted for Suicide by physical means. Hanging contributing for the maximum number of cases $15.6 \%$, followed by burns $7.1 \%$, drowning 2.1 $\%$, fall from height $0.8 \%$, railway accident $0.5 \%$ and gunshot wound $0.2 \%$ respectively, as depicted in the Figure No 7 .

Analysis of the type of poison consumed for Suicide showed that $74 \%$ of the decedents consumed some chemical substance, the most common compound being Organ phosphorous insecticide $(50.9 \%)$, other poisons and their percentage as depicted in Fig No.8

Present study showed that $20.7 \%$ of the decedents suffered from some kind of chronic physical illness disorders like Chronic Heart Disease (CHD), Diabetes, Renal failure, Bronchial asthma, Tuberculosis and Malignancy that included Carcinoma Breast, endometrial, stomach, lung and appendix. Mental illness included disorders ranging from Mental retardation, schizophrenia, bipolar disorders and depression which accounted for $3.6 \%$ of all the cases and a combination of both was observed in $2.2 \%$ of all the cases under study. There was no history of any illness in $73.5 \%$ of all the cases studied during the study period as depicted in Table No. 2.

Figure 1- Age of victims.

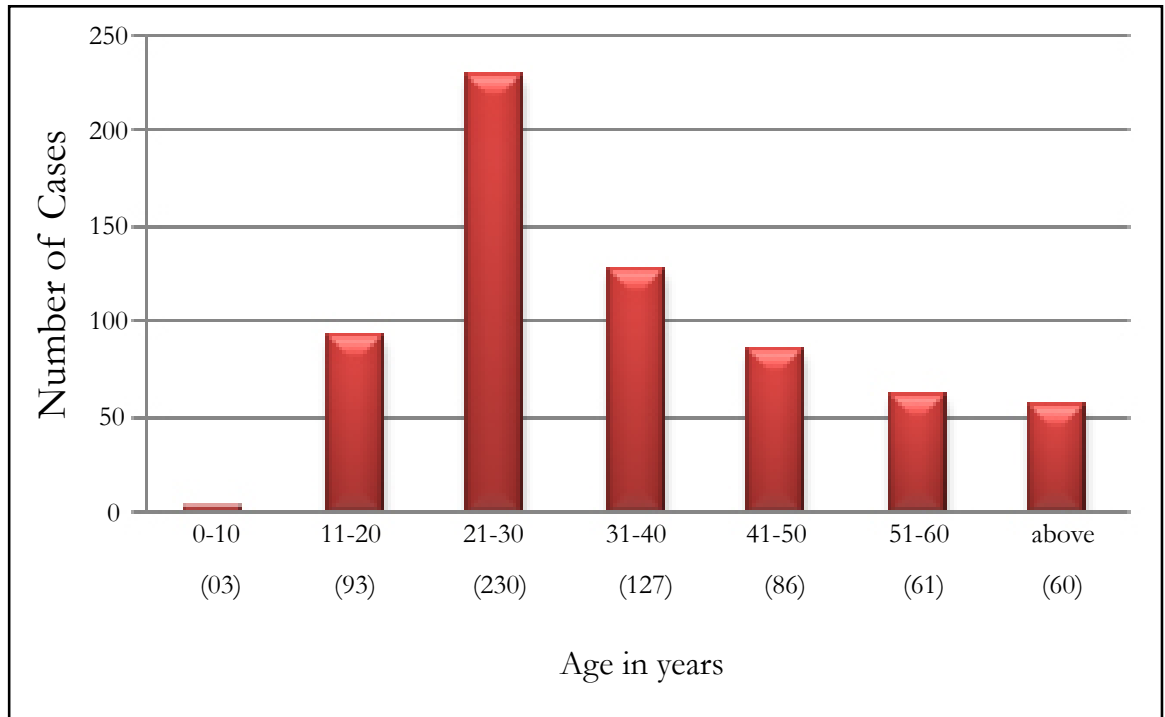


Figure2. Gender distribution of the victims

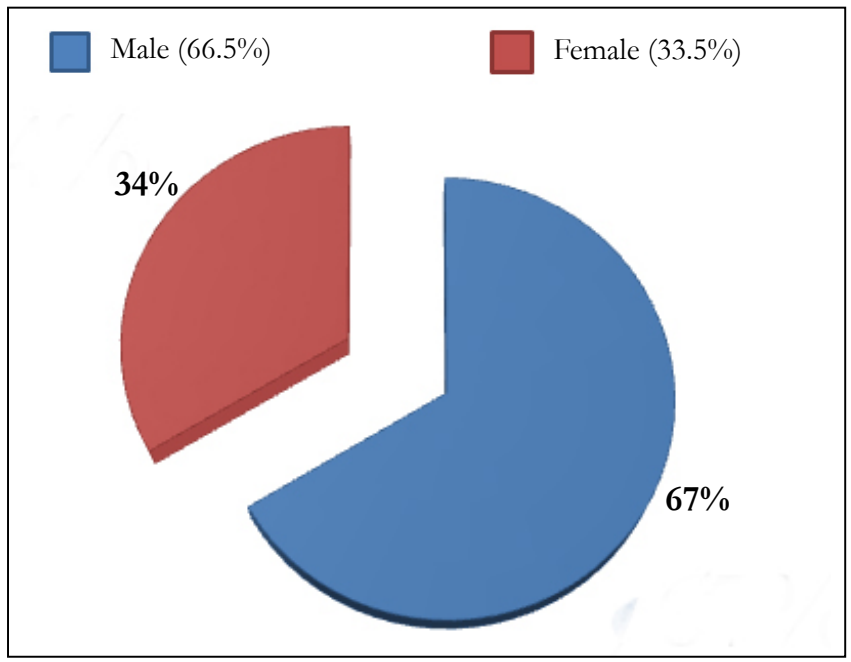

Figure 3. Marital Status of the victims

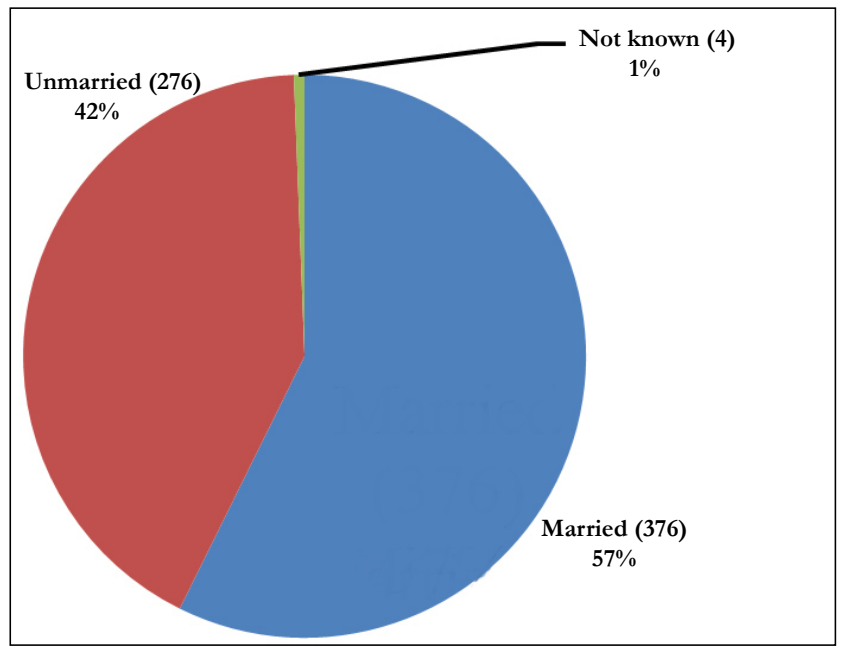

Figure 4 Religion of the victims

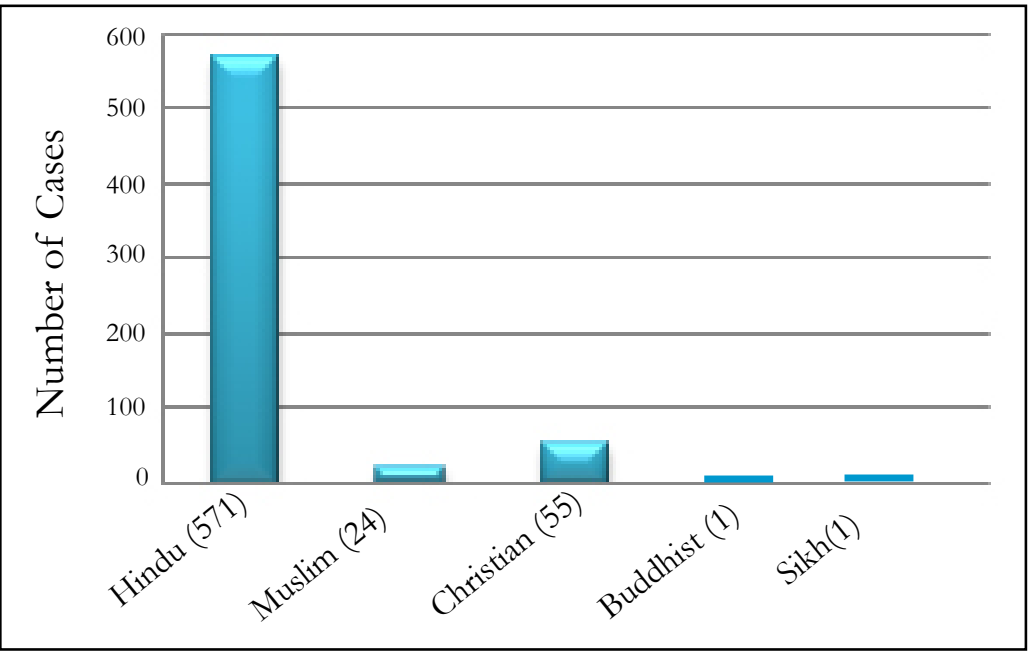

\section{Discussion}

Suicide in general, across various civilizations, has been considered as a shameful act. Although it is widely encountered, the aetiology and various complexities involved are unfortunately illunderstood. A proper understanding of these aspects is a prerequisite for suicide investigation.[1]
Suicide receives increasing attention worldwide, with many countries developing national strategies for prevention. Rates of suicide vary greatly between countries, with the greatest burdens in developing countries.

Trends of suicide vary widely according to time, region, age group, sex, and race. Despite mixed trends of increases or decreases in suicide rates around the world, suicide remains an important public-health problem. In an effort to understand and prevent suicide, 
Figure 5.Motive for Suicide

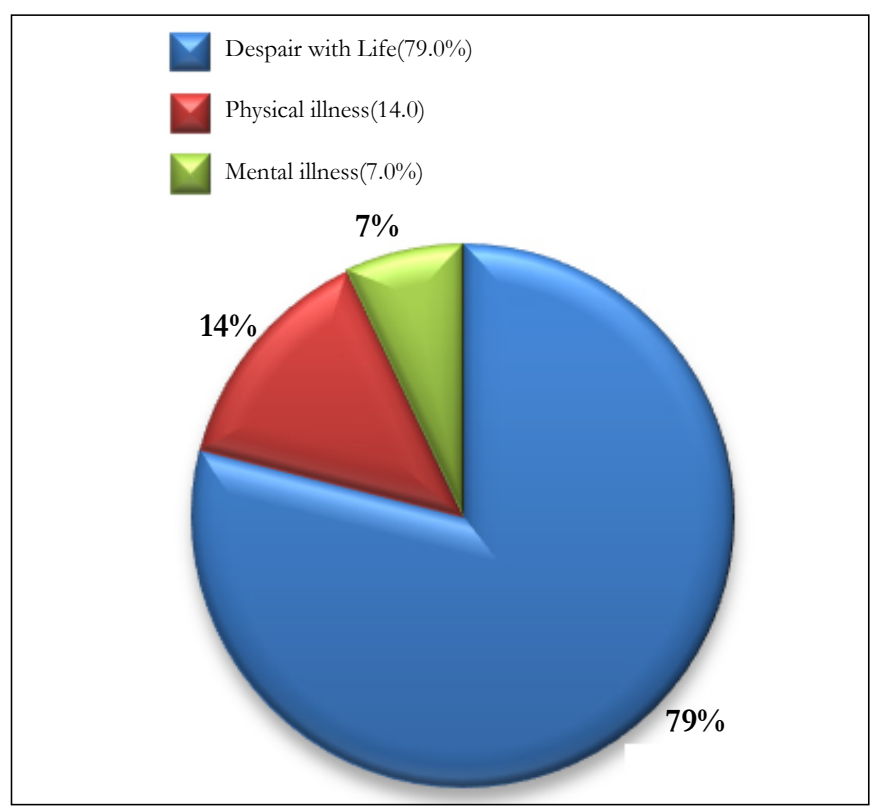

Figure6. Methods used for Suicide

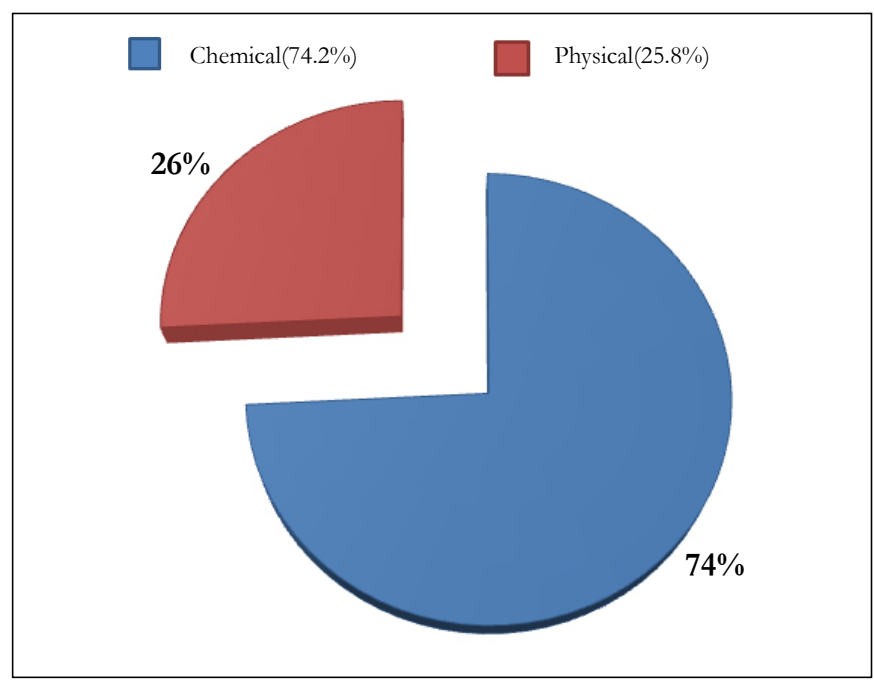

Figure 7. Physical methods adopted

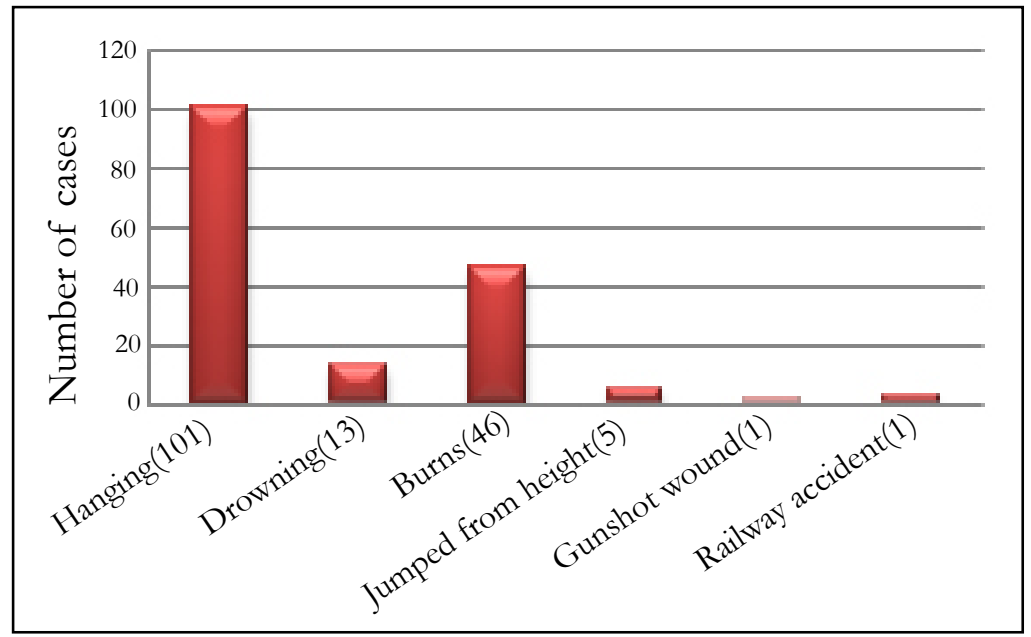

researchers have investigated medical, psychosocial, cultural, and socio-economic risk factors associated with the environment as a promising line of research.

The present study sample consisted of 656 cases of fatal deliberate self harm (FDSH) out of the 3571 total autopsy cases. The occurrence of FDSH was $18.37 \%$ of all the medico-legal autop- sies conducted (3571 cases) during the study period (1992-2012). It was $21.2 \%$ in another reported work done by Arun [1]

The present study shows that the people of all age groups were involved. The highest incidence was amongst the 21-30 years $(35.06 \%)$ followed by $31-40$ years $(19.35 \%)$. This observa- 
Figure8. Chemical methods adopted

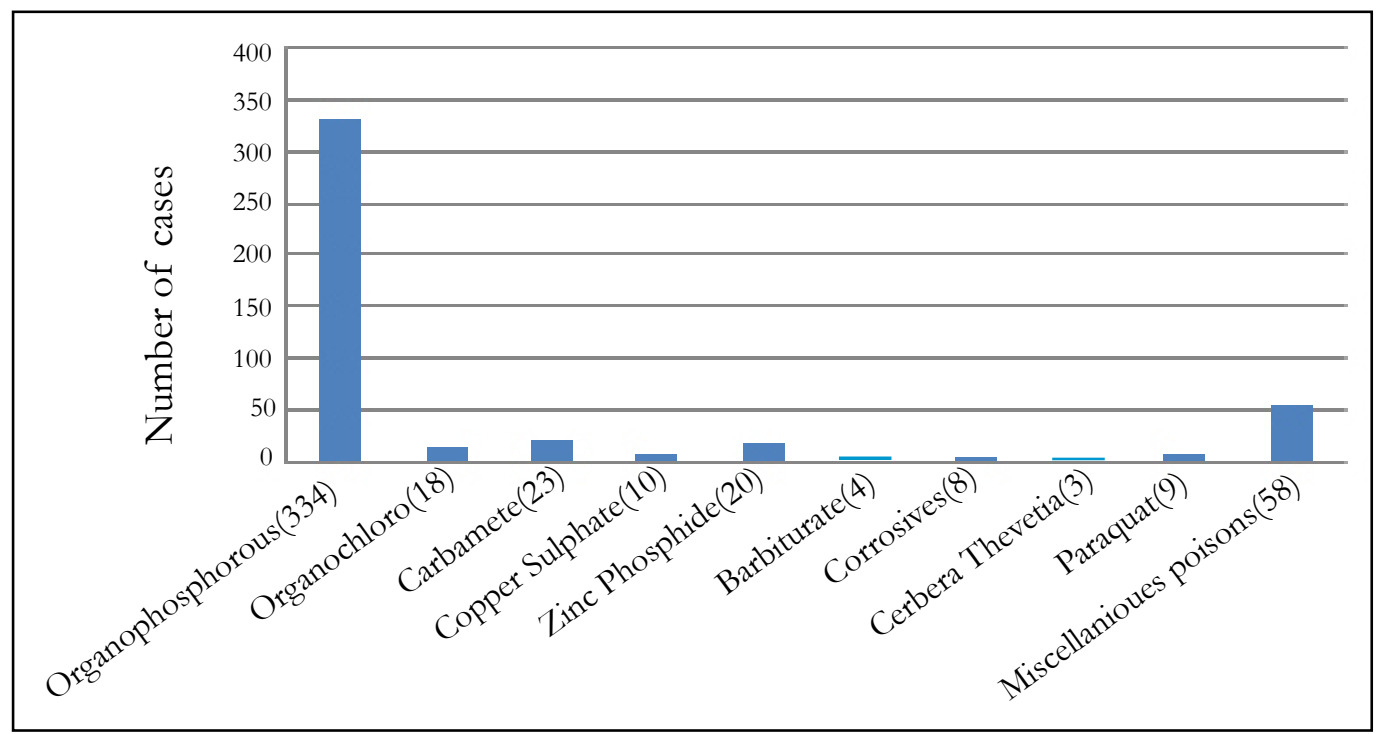

Table 1. Seasonal variation in Suicide $(n=656)$

\begin{tabular}{|l|l|l|}
\hline Seasonal variation & Number of cases & Percentage (\%) \\
\hline Winter (Nov - Feb) & 236 & 36 \\
\hline Summer (Mar - Jun) & $\mathbf{2 3 7}$ & $\mathbf{3 6 . 1}$ \\
\hline Rainy (Jul - Oct) & 183 & 27.9 \\
\hline Total & $\mathbf{6 5 6}$ & $\mathbf{1 0 0}$ \\
\hline
\end{tabular}

Table 2. History of illness $(n=656)$

\begin{tabular}{|l|l|l|}
\hline History of illness & Number of cases & Percentage ( \% ) \\
\hline Mental illness & 23 & 3.6 \\
\hline $\begin{array}{l}\text { Chronic Physical } \\
\text { Illness including Ma- } \\
\text { lignancy }\end{array}$ & 137 & 20.7 \\
\hline Combination of both & 14 & 2.2 \\
\hline No history of illness & $\mathbf{4 8 2}$ & $\mathbf{7 3 . 5}$ \\
\hline Total & $\mathbf{6 5 6}$ & $\mathbf{1 0 0}$ \\
\hline
\end{tabular}

tion was identical with the available literatures and studies done by Arun[1,2] B. D Gupta, [3] National crime record bureau [4], Sachidananda.M,[5] Behera,[6] Lisa,[9] B.R. Sharma, [11] Lalwani,[12]Fernando,[13] Gajalaxmi [16]. This is expected, as this age group comprises the majority of the population. Data from the World Health Organisation reports that adolescents and elderly individuals are at a higher risk of committing suicide. Young individuals are prone to being unable to cope with the turbulence occurring in their lives and so opt for deliberate self-harm more often. $[1,2,3,5,6,11,12]$.

But in contrast a study in Japan, Mexico and in South Carolina, USA, revealed that the most common age group of the victims was over 65 years. $[8,9]$

Male victims predominated and this finding is consistent with the findings as observed by Arun,[1,2], B. D Gupta, [3] National crime record bureau,[4] Sachidananda.M,[5] Behera,[6] S. Lalwani,[12] and Ravindra Fernando[13]. Studies in other parts of the world also showed male predominance in suicides like in Cork City, in South Carolina, USA [1,7] and in Geneva [1,7]. A study in England and Wales by Kelly and Bunting J [6.5] suggests that there is an increase in the rate of suicide in both sexes but greater in males. The reasons being that the population of males are higher than that of female's worldwide. $[1,16]$. However a literature search shows that, while men are known usually to commit suicide successfully, women have outnumbered men in non-fatal unsuccessful suicidal attempts. $[1,5,8,9]$.

But in contrast to our observations in China, and in some studies done in India females commit more suicides than males. $[1,8,9,13]$. Present study predicts marriage as being one of the important risk factors for suicide. 417 cases out of 656 cases (57.3\%) were married which is almost similar to the findings observed in other parts 
of India (65\%) [1,5,7] Married people (57.3\%) outnumbered their unmarried counterparts in Fatal deliberate self harm which is consistent with the study done by Arun,[1,2] Sachidananda.M [5]. The reason for more suicides in married ones may be linked to the two most common causes of suicides (marital disharmony and financial burden).[1] But in Thailand similar incidences of suicides among both married and unmarried have been observed. [7] However, western studies highlight that a high incidence of suicide has been observed among unmarried people. 1 The present study shows that there are probably different factors relating to marital or family life that are operating in the Indian culture. The institutions of 'marriage' and 'family' are given the utmost respect and are followed with great fervour in the Indian tradition, whereas 'live-in' relationships without marriage are more popular in the western world.[1]

Most of the victims belonged to the Hindu religion (86.4\%) followed by Christians $(8.4 \%)$ and Muslims (3.7\%) consistent with the studies done by Arun.[1,2] and Sachidananda.M. [5] In India, a major part of the population follow Hinduism as their religion. [1] Besides some isolated cases of Christians and Muslims, almost all the victims belonged to the Hindu religion. "Upanishads", the Holy scriptures of Hindus had condemned suicide and stated that 'he who takes his own life will enter the sunless areas covered by impenetrable darkness after death'. But the "Vedas" permitted suicide for religious reasons. It viewed that the best sacrifice, that could be made was one's own life.[6]

When we look at the presence of any past illness, 174 cases $(26.5 \%)$ were having some form of chronic physical and mental disorders at the time of committing suicides most commonly encountered diseases being hypertension, diabetes, malignancies of the lung, breast, stomach and mental illness including schizophrenia, bipolar disorders and depression which was similar to the studies done by A Behera, [6]. But in contrast to our findings some studies have stated that the main risk factor for both attempted and completed suicide is psychiatric disorder. [9]

Although seasonal variation is not much, however the present study reveals highest number of cases in summer season $(36.1 \%)$, followed by the winter, the rainy season witnessed the least number of fatalities which is consistent with the studies done by $\mathrm{B}$. D Gupta, [3] and Lisa.[9] But contrast to the above finding was observed in Faisalabad, where a seasonal surge was observed in spring.[5].In other studies conducted in India suicide was seen more during the winter months and in other parts of the world, [8,9] a spring peak for male and spring and autumn peaks for female suicides were found.

Despair with life due to financial restraints and family and marital disharmony constituting $79 \%$ of the total cases was the most common motive for suicide. Our findings are different from other reported works, which show a high correlation between mental illness and suicde 7 but was similar to the studies done by Arun1, 2, Lisa9, B.R. Sharma [11]. In contrast to the statistics that mental illness is a predominant cause $(90 \%$ as per WHO statistics, $51 \%$ as in Singapore and $64.5 \%$ as in Wolver Hampton), we observed only $7.1 \%$ of all suicidal cases had mental illness. The reason may be reluctance by the people of this locality to attend a clinic for simple psychiatric complains consistent with finding of Sachidananda.M.[5] Quite contrast to our findings, studies in South Carolina,[5,8] USA [9] and in Japan suggest dreadful dis- eases followed by problems of economic distress to be the two most common causes of suicide. Dreadful diseases contributed much less towards the causes of suicide in the present study.

$74.4 \%$ of the total victims in the present study used chemicals for terminating their lives and only $26.8 \%$ of the study group used physical methods for committing FDSH, which is in accordance with the various study done in India and worldwide by Arun [1,2] B.D Gupta [3] Sachidananda.M[5], and B.R. Sharma[11]. But in contrast to our study some studies done in India and abroad have shown that the physical methods are most commonly employed method for suicide. $[8,9,15]$.

Amongst those who opted for physical methods, hanging was the most common $(15.6 \%)$ followed by burns $(7.1 \%)$. This is in accordance with the findings observed by Arun,1 Sachidananda.M,5 Danielle.[8] However, in another study, in Kildare, Ireland,[1] hanging was the commonest method employed and in South Carolina,[15] suicide by gunshot was commonly noted in children under the age of 18 years. Hanging is universally available and it is the most common method of suicide globally. [1,2,3,5,6,8,9,11,15]. In many places, the ready access to firearms makes them potentially dangerous, especially among male adolescents and young adults. $[9,15]$ Death by firearm was the leading method of suicide in a study done in USA, 9, 15 accounting for $67.5 \%$ of all deaths. Regional and state-level analysis (1988-1997) of the United States demonstrated a "robust association" between the rates of household firearm ownership and suicide.15 Domestic gas has been reported in some studies as a frequently used suicide $\operatorname{method}[1,5,15]$.

Among the poisoning cases, organophosphorus poisoning (51 $\%$ ) was the most commonly used method for suicide, which is in contrast to the findings observed in England and Wales, $[8,9,15]$ wherein vehicle exhaust gas has been commonly used and carbon monoxide poisoning was common in Japan.[15]. Finding similar to our study have also been observed in India and in other countries by Arun [1,2], Sachidananda.M [5]. Miscellaneous poisons included Paraquat, Kerosene, Phosphorus, Chlorpromazine, Glyphosate and Cyanide constituting (4\%) of the total cases. People in this region have easy accessibility to organophosphorous insecticides since these are commonly used for agriculture. So whenever there is a tendency to commit suicide, these means are readily available. $[1,2,3,5,7]$.

\section{Conclusion}

There was an irregular rate in the number of suicide fatalities across the studied Twenty-year period. However, it is still considered a public health problem and should be given a high priority with regard to prevention and more research on the social and life circumstances of the affected group. We encourage further studies regarding psychological and other causes of suicide in the region. The World Health Organization's (WHO's) suicide prevention multisite intervention study on suicidal behaviours (SUPRE-MISS), an intervention study, has revealed that it is possible to reduce suicide mortality through brief, low-cost intervention in developing countries.

Suicide is a multifaceted problem and hence suicide prevention programmes should also be multidimensional. Collaboration, coordination, cooperation and commitment are needed to develop and implement a national plan, which is cost-effective, appropri- 
ate and relevant to the needs of the community. In India, suicide prevention is more of a social and public health objective than a traditional exercise in the mental health sector. The time is ripe for mental health professionals to adopt proactive and leadership roles in suicide prevention and save the lives of thousands of young Indians.

\section{Conflict of Interest}

The author has no conflict of interest to declare.

\section{Acknowledgment}

The author is thankful to Department of Forensic Medicine, Faculty of Medicine and Health Sciences, Universiti Sultan Zainal Abidin (UnisZA), Kampus Kota, Jalan Sultan Mahmud, Kuala Terengganu, 21300, Terengganu, Malaysia for encouraging research and its publication in international journals.

\section{References}

[1]. Arun M, Palimar V, Menezes RG, Babu YPR, Bhagavath P (2007). Autopsy study of fatal deliberate self harm. Med Sci Law. 47(1): 69-73.

[2]. Arun M, Palimar V, Kumar GNP, Menezes RG (2010). Unusual methods of suicide: complexities in investigation. Med Sci Law. 50(1): 149-153.

[3]. Gupta BD, Singh OG (2008). A Unique trend of murder-suicide in the
Jamnagar region of Gujarat. J Forensic Leg Med.15: 250-255.

[4]. National crime records bureau. Accidental deaths and suicides in India: ADSI 2010. Available from http://ncrb.gov.in/accdeaths.htm \{accessed on 2012 Oct 9$\}$.

[5]. Mohanty S, Sahu G, Mohanty MK, Patnaik M (2007). Suicide in India-A four year retrospective study. J Forensic Leg Med.14: 185-189.

[6]. Behera A, Balabantray JK, Nayak SR (2005). Review of Suicidal cases, A Retrospective study. J Ind Acad Forensic Med. 27 (2): 100-102.

[7]. Pridmore S (2011). Download of Psychiatry. Suicide: a broad view Chapter 31. April.

[8]. Shaw D, Fernandes JR, Rao C (2005). Suicide in Children and Adolescents. A 10 - Year Retrospective Review. Am J Forensic Med Pathol. 26: 309-315.

[9]. Shields LBE, Hunsaker DM, Hunsaker JC (2005). Suicide: A Ten- Year Retrospective Review of Kentucky Medical Examiner Cases. J Forensic Sci. 50(3): $1-5$.

[10]. Reddy MS (2010). Suicide Incidence and epidemiology. Ind J Psychol Med. 32(7): 77-82.

[11]. Sharma BR, Gupta M, Sharma AK (2007). Suicides in Northern India: Comparison of trends and review of literature. J Forensic Leg Med. 14: 318-326.

[12]. Lalwani S, Sharma GASK, Kabra SK, Girdhar S, Dogra TD (2004). Suicide among Children and adolescent in south Delhi (1991-2000). Ind J Pediatr. $71(8): 701-703$.

[13]. Fernando R, Hewagama M, Priyangika WDD, Range S, Karunaratne S (2010). Study of suicides reported to the Coroner in Colombo, Srilanka. Med Sci Law. 50: 25-28.

[14]. Kumar V (2003). Burnt Wives - A study of suicides. Burns 29: 31-35.

[15]. Suicide methods. Source: http://en.wikipedia.org/w/index. php?oldid $=499004707$ accessed on 25th September 2012\}.

[16]. Gajalakshmi V, Peto R (2007). Suicides rates in rural Tamil nadu, South India: Verbal autopsy of 39,000 deaths in 1997-98. Int J of Epidemiol. 36: 203-207. 